\title{
MULTIOBJECTIVE APPROACH TO PORTFOLIO OPTIMIZATION IN THE LIGHT OF THE CREDIBILITY THEORY
}

\author{
Fernando GARCIA (D) ${ }^{*}$, Jairo GONZÁLEZ-BUENO (D2), Francisco GUIJARRO (D) ${ }^{3}$, \\ Javier OLIVER (D) ${ }^{4}$, Rima TAMOŠIŪNIENE் ${ }^{5}$ \\ ${ }^{1,4}$ Department of Economics and Social Sciences, Universitat Politècnica de València, \\ 46022 València, Spain \\ ${ }^{2}$ Faculty of Business Administration, Universidad Pontificia Bolivariana, \\ 681017 Bucaramanga, Colombia \\ ${ }^{3}$ I.U. de Matemàtica Pura i Aplicada, Universitat Politècnica de València, 46022 Valencia, Spain \\ ${ }^{5}$ Faculty of Business Management, Vilnius Gediminas Technical University, \\ Sauletekio al. 11, LT-10223 Vilnius, Lithuania
}

Received 23 September 2019; accepted 17 May 2020

\begin{abstract}
The present research proposes a novel methodology to solve the problems faced by investors who take into consideration different investment criteria in a fuzzy context. The approach extends the stochastic mean-variance model to a fuzzy multiobjective model where liquidity is considered to quantify portfolio's performance, apart from the usual metrics like return and risk. The uncertainty of the future returns and the future liquidity of the potential assets are modelled employing trapezoidal fuzzy numbers. The decision process of the proposed approach considers that portfolio selection is a multidimensional issue and also some realistic constraints applied by investors. Particularly, this approach optimizes the expected return, the risk and the expected liquidity of the portfolio, considering bound constraints and cardinality restrictions. As a result, an optimization problem for the constraint portfolio appears, which is solved by means of the NSGA-II algorithm. This study defines the credibilistic Sortino ratio and the credibilistic STARR ratio for selecting the optimal portfolio. An empirical study on the S\&P100 index is included to show the performance of the model in practical applications. The results obtained demonstrate that the novel approach can beat the index in terms of return and risk in the analyzed period, from 2008 until 2018.
\end{abstract}

Keywords: evolutionary multiobjective optimization, fuzzy portfolio selection, mean-CVaR-liquidity, mean-semivariance-liquidity, trapezoidal fuzzy numbers, NSGA-II, credibilistic Sortino ratio, credibilistic STARR ratio.

JEL Classification: G11, G17.

*Corresponding author. E-mail: fergarga@upvnet.upv.es 


\section{Introduction}

Investors may apply different strategies to allocate their wealth in the stock markets. One option is to cherry pick the companies they want to invest in. In this case, they can individually select the companies performing fundamental analysis (Hilkevics \& Semakina, 2019; Narkunienè \& Ulbinaite, 2018) and controlling for the proper diversification (Ahmed et al., 2018; Arribas et al., 2019) or apply technical analysis (García et al., 2018b). Another option is to directly manage a portfolio of companies. In this case, the selection of the companies to be included in the portfolio is done simultaneously. When investors opt for a passive portfolio management, passive investment strategies are implemented (García et al., 2018a; Moeini, 2019). Investors preferring to adopt an active role and expecting to beat the market use other portfolio selection strategies (García et al., 2013, 2020, 2019a; Goel et al., 2018).

Portfolio selection has attracted the attention of researchers and practitioners during the last decades and is still a developing topic. The main issue to be solved is the investment of cash in the various financial assets available in the market. The principal objective is to minimize the risk of terminal wealth while the expected terminal wealth equals a prescribed level. The first breakthrough work on this topic was the seminal mean-variance model presented by Markowitz (1952). In this classical work, Markowitz used the mathematical expectation of the return obtained by the portfolio and the variance of the portfolio as return and risk measures, respectively. Since the proposal by Markowitz, portfolio theory has evolved to solve some drawbacks of the original model. Most of the research has dealt with problems such as the measurement of return and risk, the introduction of new criteria and realistic constraints, and the selection of specific portfolios on the efficient frontier.

In most studies, asset returns are assumed to be a random variable, and most portfolio selection models assume that the performance of the assets in the future can be calculated correctly using the performance they had in the past. However, as stock markets are affected by an enormous number of factors, there are more uncertainty types other than randomness in the actual markets. To solve this issue, Zadeh introduced the fuzzy set theory (Zadeh, 1965 ) in order to capture and model the portfolio investment. A vast number of studies have assumed the fuzziness of returns and have utilize possibility measures to select the assets to be included in the investment portfolio (Carlsson et al., 2002; Gupta et al., 2020b; Y. J. Liu \& Zhang, 2018; Mansour et al., 2019; Vercher et al., 2007; Vercher \& Bermúdez, 2012; Wang $\&$ Zhu, 2002). Possibility measures are widely used, but they are not self-dual. Liu and Liu (2002) proposed as an alternative a credibility measure which is self-dual in order to solve the problems incurred by the possibility measure. Since then, some researchers suggest modeling assets return using credibility measures (García et al., 2013; González-Bueno, 2019; Gupta et al., 2020a; Huang, 2006, 2009; Mehlawat, 2016; Vercher \& Bermúdez, 2015). The credibility measure is consistent with the law of excluded middle and the law of contradiction (i.e., they have the self-duality property) (Huang, 2010), which is required in theory and demanded by practitioners. In the last years, researchers have devoted attention to uncertain portfolio selection based on the uncertainty theory, which is an extension of the credibility theory (Huang, 2017; Huang \& Di, 2016; Huang \& Wang, 2019; Huang \& Yang, 2020; Mehralizade et al., 2020; Zhai \& Bai, 2018). 
Risk measurement has been improved, as well. When portfolio returns are typically asymmetric, the variance is not an adequate option to quantify risk, because it considers high positive returns desired by investors as a risky evolution of the portfolio. This is not correct, as only negative returns are associated to risk by investors (X. Li \& Qin, 2014). In other words, the variance penalizes extreme deviations from the expected return, regardless the sign (positive or negative) of the deviations (Gupta et al., 2013b). To approach this issue, a number of downside risk measures (i.e. measures that only take into account undesirable low returns compared to the expected return level) have been proposed: semivariance (Markowitz, 1959), lower partial moment (Bawa, 1975; Fishburn, 1977), semi-absolute deviation (Speranza, 1993), value at risk (VaR) (Morgan, 1996), and conditional value at risk (CVaR) (Rockafellar \& Uryasev, 2000, 2002). Among those risk measures, semivariance and CVaR are the most commonly accepted downside risk measures. Semivariance and CVaR separate negative downside deviations of returns from the positive deviations which are welcome by investors and just consider on those returns which fall below a specific level (Huang, 2008). As a result, they are more appropriate to reflect investors' concern about downside losses (Bi et al., 2013). Experimental studies have shown the merits of semivariance and CVaR in measuring portfolio risk in both random (Acerbi \& Tasche, 2002; Artzner et al., 1999; Choobineh \& Branting, 1986; Kaplan \& Alldredge, 1997; Markowitz et al., 1993; Pflug, 2000; Zhao et al., 2020) and fuzzy (Bai \& Liu, 2015; Chen \& Xu, 2019; García et al., 2019b; Gupta et al., 2020a; Huang, 2008; Jalota et al., 2017a, 2017b) environments.

In the traditional portfolio selection model, investor choices are governed by two basic criteria: return and risk (Bezoui et al., 2019; Heidari-Fathian \& Davari-Ardakani, 2020; Konno \& Yamazaki, 1991; B. Li et al., 2018; Markowitz, 1952; Speranza, 1993). Nevertheless, it is important to consider more criteria apart from return and risk which are also valuable for investors, and are considered by them in their actual portfolio selection process. By taking into account additional criteria in the selection process, it may occur that the new portfolios are, on the one hand, not as profitable or more risky but, on the other hand, beat the old portfolios regarding other important aspects for investors, such as liquidity (Gupta et al., 2013a).

Together with return and risk, one of the fundamental criteria employed by actual investors to build their portfolios is liquidity. Several previous studies on portfolio decision-making have included liquidity as a fuzzy variable (Arenas-Parra et al., 2001; Gupta et al., 2010, 2011; Jalota et al., 2017a, 2017b; Mansour et al., 2019; Yue et al., 2019). Generally, investors' preference is to own portfolios that contain liquid assets which can be easily liquidated in the future. Consequently, in our research we will include liquidity in the decision-making approach, together with return and risk, in order to make the mean-semivariance model more realistic and usable in a real situation.

An important aspect to consider in fuzzy portfolio optimization is the shape of the membership functions, so that the functions can properly represent the historical performance of the stocks. For the purpose of addressing this issue, some papers model the risk associated with future returns applying trapezoidal fuzzy numbers (Gupta et al., 2013a, 2013b; H. Q. Li \& Yi, 2019; N. Liu et al., 2018; Mehlawat et al., 2020; Rubio et al., 2016; Vercher et al., 2007). These kind of fuzzy variables will allow to analyze not only the expected return, but also the risk associated with of a specific asset or portfolio (Rubio et al., 2016). In addition, the use 
of trapezoidal fuzzy variables is widespread to approach different issues as they are easy to calculate (Gupta et al., 2014a). Due to the above considerations, in this study we model the uncertainty of both the future returns and the liquidity of the potential stocks to be included in the portfolio by means of trapezoidal fuzzy numbers.

The mean-variance model by Markowitz generates an efficient frontier composed by many different portfolios. But, in fact, this solution does not solve the demands by investors, as they still have to choose one specific portfolio on the efficient frontier. Following Sharpe (1966) an option to select one specific portfolio is choosing the one which maximizes the risk-adjusted returns. Since Sharp, many portfolio risk measures have been proposed, for example the Treynor ratio (Treynor, 1965), the Sharpe ratio (Sharpe, 1994), the Sortino ratio (Sortino \& Price, 1994), the Omega ratio (Keating \& Shadwick, 2002), the VaR ratio (Favre \& Galeano, 2002; Martin et al., 2003) or the STARR ratio (Martin et al., 2003).

In this article, we suggest the use of a credibilistic multiobjective model, where return, risk and liquidity are considered to quantify portfolio performance. Both return and liquidity are included in the model as trapezoidal fuzzy numbers. In the decision-making process this approach considers a number of realistic constraints required by investors. Specifically, the expected return, the semivariance or $\mathrm{CVaR}$ and the expected liquidity of the portfolios are optimized while including in the model budget, bound and cardinality constraints. These realistic constraints included in the model convert the problem into a NP-hard problem which cannot be solved by means of traditional methods of optimization. To solve this concern, the Non-dominated Sorting Genetic Algorithm II (NSGA-II) is employed. In order to select specific portfolios, the credibilistic Sortino ratio and the credibilistic STARR ratio are defined. Finally, the proposed approach is used employing actual data of the stock exchange to show its efficiency and that it can actually be used by practitioners.

The remainder of the article is structured as follows: The first section introduces some core definitions and notations regarding trapezoidal fuzzy numbers and the credibility theory. Section 2 describes the multiobjective credibilistic return-risk-liquidity portfolio selection model. Section 3 presents the solution methodology used to figure out the above model with the NSGA-II algorithm. Section 4 illustrates our proposal with an empirical study. The main conclusions of the paper are presented in last Section.

\section{Credibility theory}

The credibility theory, was first introduced by Liu (2004) and then further developed by Liu (2007). This theory deals with the study fuzzy phenomena. Hereunder we recall the basic definitions and notations that will be used in the paper.

Definition 1. Credibility measure (B. Liu \& Liu, 2002). Let $\xi$ be a fuzzy variable with membership function $\mu_{\xi}$, and $\mathrm{x}$ a real number. Then for any fuzzy event (characterized by $\xi \leq$ $\mathrm{x})$ the credibility measure is defined by Eq. (1):

$$
\operatorname{Cr}\{\xi \leq x\}=\frac{1}{2}\left(\sup _{y \leq x} \mu_{\xi}(y)+1-\sup _{y>x} \mu_{\xi}(y)\right), \forall x \in R .
$$


Definition 2. Trapezoidal fuzzy number. A fuzzy number $\delta$ is called a trapezoidal fuzzy number if it is defined by the quadruplet $(a, b, c, d)$ and its function of membership is given as follows:

$$
\mu_{\delta}(x)=\left\{\begin{array}{ll}
\frac{x-a}{b-a}, & \text { if } a \leq r \leq b \\
1, & \text { if } b \leq r \leq c \\
\frac{d-x}{d-c}, & \text { if } c \leq x \leq d \\
0, & \text { otherwise }
\end{array},\right.
$$

where $[a, d]$ and $[b, c]$ are defined as the support and core of the $\delta$, respectively. $(b-a)$ and $(\mathrm{d}-\mathrm{c})$ are called the left and right spreads of $\delta$, respectively. Then, the credibility measure $\operatorname{Cr}\{\xi \leq \mathrm{x}\}$ of a trapezoidal fuzzy number is obtained deriving the Eq. (1):

$$
\operatorname{Cr}\{\xi \leq x\}= \begin{cases}0, & \text { if } r \leq a \\ \frac{x-a}{2(b-a)}, & \text { if } a \leq x \leq b \\ \frac{1}{2}, & \text { if } b \leq x \leq c . \\ \frac{d-2 c+x}{2(d-c)}, & \text { if } c \leq x \leq d \\ 1, & \text { if } d \leq x\end{cases}
$$

Definition 3. Expected value (B. Liu \& Liu, 2002). Let $\xi$ be a fuzzy variable. Then, provided that at least one of the two integrals is finite, the expected value of $\xi$ is defined by Eq. (2):

$$
\mathrm{E}(\xi)=\int_{0}^{+\infty} \operatorname{Cr}\{\xi \geq \mathrm{x}\} \mathrm{dx}-\int_{-\infty}^{0} \operatorname{Cr}\{\xi \leq \mathrm{x}\} \mathrm{dx} .
$$

From Eq. (2), it can be derived that the credibilistic expected value of a trapezoidal fuzzy number is given by Eq. (3).

$$
E(\xi)=\frac{a+b+c+d}{4} .
$$

Definition 4. Semivariance (B. Liu \& Liu, 2002). Let $\xi$ be a fuzzy variable with finite expected value $\mathrm{e}=\mathrm{E}[\xi]$. Then the semivariance of $\xi$ is defined by Eq. (4).

$$
\mathrm{SV}[\xi]=\mathrm{E}\left[\left([\xi-\mathrm{e}]^{-}\right)^{2}\right],
$$

where,

$$
[\xi-\mathrm{e}]^{-}=\left\{\begin{array}{ll}
\xi-\mathrm{e}, & \text { if } \xi \leq \mathrm{e} \\
0, & \text { if } \xi>\mathrm{e}
\end{array} .\right.
$$

From Eq. (2) and Eq. (4), the credibility-measure-based semivariance of a trapezoidal fuzzy number is given by Eq. (5): 


$$
\operatorname{SV}[\xi]= \begin{cases}\frac{(e-a)^{3}}{6(b-a)}, & \text { if } e<b \\ \frac{(b-a)(3 e-2 b-a)+3(e-b)^{2}}{6}, & \text { if } b \leq e \leq c . \text { (5) } \\ \frac{(b-a)(3 e-2 b-a)+3(c-b)(2 e-b-c)}{6}+\frac{(c-e)^{2}(3 d-4 c+e)}{6(d-c)}, & \text { if } e>c\end{cases}
$$

Definition 5. Conditional Value at Risk (CVaR) (Bai \& Liu, 2015). Let $\xi$ be a fuzzy variable and $\beta \in(0,1]$ be the confidence level. Then the $C V a R$ of $\xi$ is defined by Eq. (6).

$$
\mathrm{CVaR}_{\beta}[\xi]=\inf \{\mathrm{x} \mid \mathrm{Cr}\{\xi \leq \mathrm{x}\} \geq \beta\} .
$$

Finally, the credibilisticCVaR of a trapezoidal fuzzy number is given by Eq. (7).

$$
\mathrm{CVaR}_{\beta}[\xi]=\left\{\begin{array}{ll}
\mathrm{a}+2 \beta(\mathrm{b}-\mathrm{a}), & \text { if } \beta \in(0,0.5] \\
2 \mathrm{c}-\mathrm{d}+2 \beta(\mathrm{d}-\mathrm{c}), & \text { if } \beta \in(0.5,1]
\end{array} .\right.
$$

\section{Multiobjective credibilistic return-risk-liquidity portfolio selection model}

Next, we will introduce the proposed model to solve the multiobjective portfolio selection problem in the light of the credibility theory. But first, we will define the parameters and the decision-making variables that will be employed in the mathematical model:

\section{Parameters}

$\xi_{\mathrm{r}_{\mathrm{i}}}$ : fuzzy rate of return of the $\mathrm{i}$-th asset denoted by a trapezoidal fuzzy number, $\xi_{r_{i}}=\left(a_{r_{i}}, b_{r_{i}}, c_{r_{i}}, d_{r_{i}}\right)$,

$\xi_{l_{i}}$ : fuzzy liquidity of the $i$-th asset denoted by a trapezoidal number $\xi_{l_{i}}=\left(a_{l_{i}}, b_{l_{i}}, c_{l_{i}}, d_{l_{i}}\right)$, $\xi_{r_{p}}$ : fuzzy return of the portfolio denoted by a trapezoidal fuzzy number $\xi_{r_{p}}^{p}=\left(a_{r_{p}}, b_{r_{p}}, c_{r_{p}}, d_{r_{p}}\right)$,

e: portfolio's expected return,

$\mathrm{u}_{\mathrm{i}}$ : maximal percentage of the capital to be allocated to the $\mathrm{i}$-th asset,

$1_{\mathrm{i}}$ : minimal percentage of the capital to be allocated to the $\mathrm{i}$-th asset,

$\mathrm{k}$ : number of assets that are included in the investment portfolio.

\section{Decision variables}

$\omega_{\mathrm{i}}$ : share of the available funds which have been used to purchase the i-th asset,

$\mathrm{y}_{\mathrm{i}}$ : a binary variable which specifies whether the $\mathrm{i}$-th asset is included, or not, in the portfolio. When the i-th asset is included in the portfolio the value of the variable is 1 , and if the asset is not included, the value is 0 . 


\subsection{Objective functions}

\section{Return}

Considering that in the financial markets there are several non-probabilistic factors that have an influence on the return of assets, this paper assumes that an investment manager has decided to allocate her investment budget among $\mathrm{n}$ assets which have fuzzy returns. As proposed by Bermúdez et al. (2012), Vercher et al., (2007) and Yue and Wang (2017), we consider the observations of the historical dataset of the returns as a sample, so this study uses the sample percentiles to approximate the support and core of the trapezoidal fuzzy returns on the assets. In this sense, the support of $\xi_{r_{i}}$, that is, the interval $\left[a_{r_{i}}, d_{r_{i}}\right]$ is given by the 5 th and 95th percentile, respectively. The core of $\xi_{r_{i}}$, that is, the interval $\left[b_{r_{i}}, c_{r_{i}}\right]$ is given by the 40th and $60^{\text {th }}$ percentile, respectively. Thus, we can express the maximization of the expected return of the portfolio as follows:

\section{Liquidity}

$$
\operatorname{Max} F_{1}\left(\omega_{i}\right)=\sum_{i=1}^{n}\left[\left[\frac{a_{r_{i}}+b_{r_{i}}+c_{r_{i}}+d_{r_{i}}}{4}\right] \omega_{i}\right] .
$$

Liquidity is a key issue that concerns investors during the portfolio selection process. Liquidity can be defined as the probability of converting an investment into cash without any significant loss in value (Arenas-Parra et al., 2001; Gupta et al., 2013b). Generally, investors prefer portfolios which can be liquidated at higher expected values as well as portfolios for which liquidation values are more certain. By following Arenas-Parra et al. (2001), Fang et al. (2006) and Gupta et al. (2013b), this study defines the asset's liquidity using the turnover rate which is defined by the ratio of the average trading volume of the stocks traded in the market and the trading volume of the tradable stock (i.e., shares held by the public) corresponding to the asset.

Owing to incomplete information, the turnover rates are only vague estimates. Therefore, this study assumes that the turnover rate is a fuzzy number. The core and support of the trapezoidal fuzzy liquidity are obtained from the empirical percentiles of the historical data of liquidity, as previously explained. Then, the maximization of the expected liquidity of the portfolio can be expressed as:

\section{Risk}

$$
\operatorname{Max}_{2}\left(\omega_{\mathrm{i}}\right)=\sum_{\mathrm{i}=1}^{\mathrm{n}}\left[\left[\frac{\mathrm{a}_{\mathrm{l}_{\mathrm{i}}}+\mathrm{b}_{\mathrm{l}_{\mathrm{i}}}+\mathrm{c}_{\mathrm{l}_{\mathrm{i}}}+\mathrm{d}_{\mathrm{l}_{\mathrm{i}}}}{4}\right] \omega_{\mathrm{i}}\right]
$$

In this research, we will employ two alternative risk measures: semivariance and CVaR. The minimization of portfolio's semi-variance is denoted as:

$$
\operatorname{Min} F_{3}\left(\omega_{i}\right)= \begin{cases}\frac{\left(e-a_{r_{p}}\right)^{3}}{6\left(b_{r_{p}}-a_{r_{p}}\right)}, & \text { if } e<b_{r_{p}} \\ \frac{\left(b_{r_{p}}-a_{r_{p}}\right)\left(3 e-2 b_{r_{p}}-a_{r_{p}}\right)+3\left(e-b_{r_{p}}\right)^{2}}{6}, & \text { if } b_{r_{p}} \leq e \leq c_{r_{p}} . \\ \frac{\left(b_{r_{p}}-a_{r_{p}}\right)\left(3 e-2 b_{r_{p}}-a_{r_{p}}\right)+3\left(c_{r_{p}}-b_{r_{p}}\right)\left(2 e-b_{r_{p}}-c_{r_{p}}\right)}{6}+\frac{\left(c_{r_{p}}-e\right)^{2}\left(3 d_{r_{p}}-4 c_{r_{p}}+e\right)}{6\left(d_{r_{p}}-c_{r_{p}}\right)}, & \text { if } e>c_{r_{p}}\end{cases}
$$


The minimization of portfolio's CVaR is denoted as:

$$
\operatorname{Min} F_{3}\left(\omega_{i}\right)=\left\{\begin{array}{ll}
\sum_{i=1}^{n} w_{i}[a+2 \beta(b-a)], & \text { if } \beta \in(0,0.5] \\
\sum_{i=1}^{n} w_{i}[2 c-d+2 \beta(d-c)], & \text { if } \beta \in(0.5,1]
\end{array} .\right.
$$

\subsection{Constraints}

In order to account for some common realistic problems faced by investors, several constraints have been included in the decision problem.

All the available investment budget must be allocated

$$
\sum_{i=1}^{n} \omega_{i}=1
$$

Selling short is not allowed

$$
\omega_{\mathrm{i}} \geq 0, \mathrm{i}=1,2, \ldots, \mathrm{n} .
$$

There is a maximum rate of the available budget that can be used to invest in a single asset

$$
\omega_{i} \leq u_{i} y_{i}, \quad i=1,2, \ldots, n .
$$

It is not allowed to invest in an asset less than a determined rate of the available budget

$$
\omega_{i} \geq l_{i} y_{i}, \quad i=1,2, \ldots, n .
$$

The number of assets included in the portfolio is denoted as

$$
\sum_{i=1}^{n} y_{i}=k, y_{i} \in\{0,1\}, i=1,2, \ldots, n .
$$

\subsection{Definition of the decision problem}

The formulation of the credibilistic model which considers as decision-making criteria return, risk and liquidity is expressed as:

$$
\begin{aligned}
& \operatorname{Max} F_{1}\left(\omega_{i}\right) \quad \operatorname{Max} F_{2}\left(\omega_{i}\right) \quad \operatorname{Min} F_{3}\left(\omega_{i}\right) \\
& \text { s.t. } \begin{cases}\sum_{i=1}^{n} \omega_{i}=1, & i=1,2, \ldots, n \\
\omega_{i} \geq 0, & i=1,2, \ldots, n \\
\omega_{i} \leq u_{i} y_{i}, & i=1,2, \ldots, n \\
\omega_{i} \geq l_{i} y_{i}, & i=1,2, \ldots, n \\
n & \\
\sum_{i=1}^{n} y_{i}=k & \\
y_{i} \in\{0,1\}, & i=1,2, \ldots, n\end{cases}
\end{aligned}
$$


Following Vercher and Bermúdez (2013) an eligible portfolio $\mathrm{P}^{\mathrm{e}}$ is defined as Paretoefficient if no other eligible portfolio $\mathrm{P}^{\mathrm{o}}$ exists so that $\mathrm{P}_{\mathrm{F}_{1\left(\omega_{\mathrm{i}}\right)}^{o}} \geq \mathrm{P}_{\mathrm{F}_{1\left(\omega_{\mathrm{i}}\right)}}^{\mathrm{e}}, \mathrm{P}_{\mathrm{F}_{2\left(\omega_{\mathrm{i}}\right)}}^{\mathrm{o}} \geq \mathrm{P}_{\mathrm{F}_{2\left(\omega_{\mathrm{i}}\right)}}^{\mathrm{e}}$, and $\mathrm{P}_{\mathrm{F}_{3\left(\omega_{\mathrm{i}}\right)}}^{\mathrm{o}} \leq \mathrm{P}_{\mathrm{F}_{3\left(\omega_{\mathrm{i}}\right)}}^{\mathrm{e}}$, with at least one strict inequality. The efficient frontier is composed by all portfolios which are Pareto-efficient, and represents a surface when drawn in the 3-D space of the three objectives $\mathrm{F}\left(\mathrm{F}_{1}, \mathrm{~F}_{2}, \mathrm{~F}_{3}\right)$.

\subsection{Portfolio selection}

The multiobjectivecredibilistic return-risk-liquidity portfolio selection model is formulated as: Once the Pareto optimal frontier or efficient frontier is obtained, the next step is to select a portfolio on this frontier. In this study, two ratios are employed to this end, depending on the risk measure used. When the semivariance is used as to quantify risk, the Sortino ratio is applied. In the case of the CVaR, the STARR ratio is used.

The Sortino ratio is a modification of the Sharpe ratio and employs the semivariance to gauge volatility so that only returns below a certain threshold are penalized. The Sortino ratio in a credibilistic environment is computed as:

$$
\text { Sortino ratio }=\frac{E\left(\xi_{\mathrm{p}}\right)-\mathrm{E}\left(\xi_{\mathrm{Rf}}\right)}{\mathrm{SV}\left(\xi_{\mathrm{p}}\right)},
$$

where, $\mathrm{E}\left(\xi_{\mathrm{p}}\right)$ denotes portfolio's expected fuzzy return, $\operatorname{SV}\left(\xi_{\mathrm{p}}\right)$ denotes the fuzzy semivariance, and $E\left(\xi_{\mathrm{Rf}}\right)$ stays for the required profitability of the investment.

The STARR ratio focuses on the risk of extreme losses and serves to value the expected excess return for unit of risk represented by CVaR. In a credibilistic environment this ratio is computed as follows:

$$
\text { STARR ratio }=\frac{E\left(\xi_{p}\right)-E\left(\xi_{\mathrm{Rf}}\right)}{\operatorname{CVaR}\left(\xi_{\mathrm{p}}\right)},
$$

where, $\mathrm{E}\left(\xi_{\mathrm{p}}\right)$ represents portfolio's expected fuzzy return, $\operatorname{CVaR}\left(\xi_{\mathrm{p}}\right)$ denotes the fuzzy $\mathrm{CVaR}$ measure and $\mathrm{E}\left(\xi_{\mathrm{Rf}}\right)$ expresses the required profitability of the investment.

\section{Use of NSGA-II to solve the proposed model}

In the previous section, we have presented a multiobjective credibilistic portfolio selection model in which the crisp goals of return, risk and liquidity are the objective functions. Note that the calculation of the expected return, the risk and the expected liquidity is influenced by two factors i) the attributes of the trapezoidal fuzzy returns and trapezoidal fuzzy liquidity of each asset, and ii) the average of the fuzzy numbers. Furthermore, the inclusion of real-world constraints into the suggested model changes the former classical quadratic optimization problem into a NP-hard quadratic mixed-integer one. In order to overcome this drawback, the constrained portfolio optimization problem has been approached employing multiobjective evolutionary algorithms (MOEAs). NSGA-II, which was introduced by Deb, Agrawal, Pratap and Meyarivan (2002) is commonly employed MOEA to deal with this kind of optimization problems (Liagkouras \& Metaxiotis, 2015). Our study employs NSGA-II to solve the proposed model. 


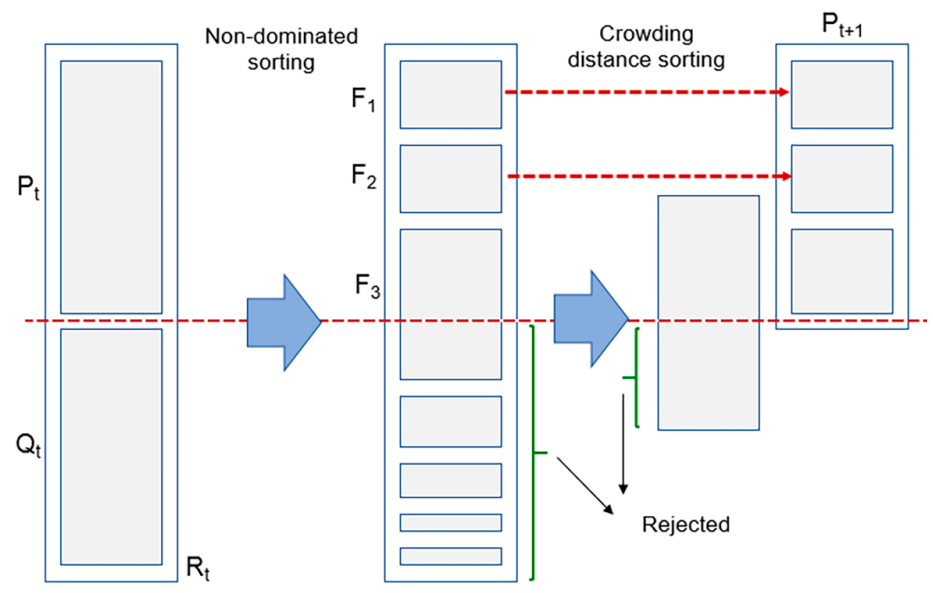

Figure 1. NSGA-II Procedure

NSGA-II is an improved version of NSGA (Srinivas \& Deb, 1994). Compared to its predecessor, NSGA-II has three significant features: i) a fast efficient non-dominated sorting scheme that reduces the computational complexity; ii) an elitist selection method for capturing the Pareto optimal front; and iii) a crowding-distance operator for preserving the diversity in the population.

Briefly, the main loop (Figure 1) of NSGA-II can be described as follow (Deb et al., 2002; Palanikumar et al., 2009):

Step 1: A combined population (parent and offspring) $R_{t}=P_{t} \cup Q_{t}$ of size $2 N$ is formed, and the resulting population is classified using a fast non-domination procedure. As a result of this step, different non-dominated fronts $\mathrm{F}_{1}, \mathrm{~F}_{2}$, etc. are obtained;

Step 2: To obtain the new parent population $\mathrm{P}_{t+1}$ the solutions from the first front $\mathrm{F}_{1}$ and continuing are added until the size exceeds $\mathrm{N}$;

Step 3: Next, we sort the solutions of the last accepted front applying a crowded-comparison criterion $(\prec \mathrm{n})$, then the first $\mathrm{N}$ points are chosen;

Step 4: We construct the population $\mathrm{P}_{\mathrm{t}+1}$ of size $\mathrm{N}$ utilizing the method described in which selection, crossover and mutation are employed to generate the new population $\mathrm{Q}_{t+1}$ of size $\mathrm{N}$.

Step 5: The optimal portfolio is selected among all non-dominated portfolios applying the proposed credibilistic Sortino ratio or the credibilistic STARR ratio, depending on the risk measure employed.

Once the general characteristics of NSGA-II have been presented, we have to specify the experimental configuration of the parameters that will be used to test the real-world applicability of the presented approach: the size of the population is 400 , the distribution index for crossover is set at 10; the probability of crossover is set at 0.9 ; the distribution index for mutation is 50 ; the probability of mutation is 0.01 ; and the maximum number of generations is limited at 500. Figure 2 displays the general framework of the proposed approaches. 


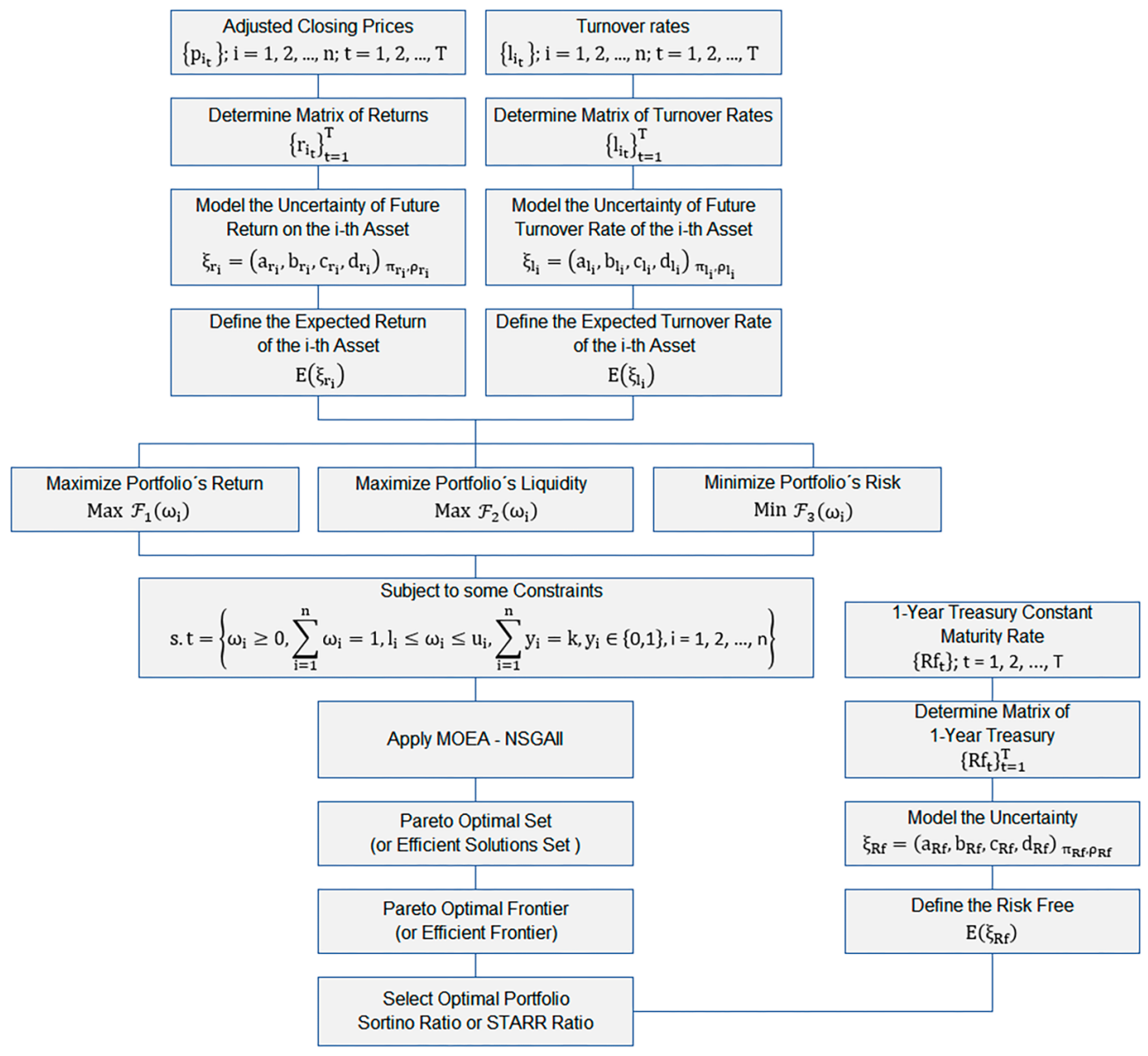

Figure 2. General framework of the proposed approaches

\section{Empirical study}

\subsection{Database and experiment description}

In order to present the performance of the model introduced above, here we illustrate a realistic empirical analysis on stocks included in the American S\&P 100 stock index using data provided by Economatica. Two models will be introduced, as we will use two alternative risk measures: semivariance and CVaR. The data correspond to adjusted prices in a one-week timeframe and stock liquidity. The data cover $t=829$ weeks from 2003/02/14 to 2018/12/28. Returns of asset $r_{i t}$ are calculated as $r_{i t}=\left(p_{i t}-p_{i t-1}\right) /\left(p_{i t-1}\right), i=1,2, \ldots, n ; t=1,2, \ldots, 829$, where $p_{i t}$ is the closing price of the $i$-th asset on Friday of week $t$.

By employing the stocks included in this stock index makes it is possible to compare the outcome obtained by the models which have been described in the previous sections and the S\&P 100 ETF, which acts as the benchmark. This comparison, however, will only be possible regarding return and risk, as no data are available regarding ETF liquidity. 
Following Gupta, Mehlawat, Inuiguchi and Chandra (2014b) a portfolio should not hold too many assets nor too few. While it is not necessary to hold many assets to achieve a correct diversification, if the number of assets in the portfolio is too reduced, it is not possible to correctly manage risks. Thus, following this recommendation, this study considers to set $\mathrm{k}=10$ as the number of assets to be hold in the portfolio.

We also apply an upper bound constraint of $30 \%$ and a lower bound constraint of $5 \%$. This means that the investor is not willing to invest more than $30 \%$ nor less than $5 \%$ of the budget in one stock, which are usual limits by investors. These assumptions are feasible and consistent with practical investment making scenarios recorded in literature (Gupta et al., 2020a, 2013b; Jalota et al., 2017a; Saborido et al., 2016; Vercher \& Bermúdez, 2013, 2015).

Using a window of 5 years, each model obtains a portfolio, that is, each model defines the stocks that must be incorporated in the investment portfolio and their weights. The performance of this portfolio is then tracked during the next six months. Then, the models are again optimized using the information of the last 5 years, i.e., moving the previous window forward six months. This procedure has been repeated 20 times, so the portfolios have been recalculated 20 times in the period from 2008 to 2018 using 20 overlapping rollingwindows. Doing this, it is possible to contrast the performance of the models in a 10-years out-of-sample period in a realistic situation where investors rebalance their portfolios twice a year.

\subsection{Results}

As a first step, the models obtain the efficient frontier, which is composed by many alternative portfolios, each of which contains different stocks with different weights.

Figures 3 and 4 show 3 -dimensional plots of the final populations generated by NSGA-II for the semivariance and CVaR models, respectively, which correspond to the last period analyzed, the one from June 2013 to June 2018, which is used to select the portfolio to be hold in the second semester of 2018. The outcome for the other periods is very similar. The points represent the set of efficient portfolios (also called non-dominated portfolios). It is not possible to find a portfolio which can beat any of the portfolios on the efficient frontier regarding the three criteria employed in the selection process, that is, return, liquidity and risk. NSGA-II supplies sets of efficient portfolios distributed on Pareto's optimal front, providing investors with an accurate and real illustration of the trade-offs.

Figures 3 and 4 reveal the similar shape of the efficient frontier obtained depending on the risk measure applied, regarding the relationship between the three criteria (return, risk and liquidity).

In order to analyze this relationship, Spearman's rank partial correlation coefficient is applied. Doing this, we can better assess the relationship between risk and return, as we can erase the impact of liquidity on this relationship. We expect both variables to have a positive correlation. Furthermore, thanks to Spearman's rank partial correlation coefficient we can get to know the connection of return and risk with liquidity. Table 1 shows that the correlation between return and risk is positive, which means that those portfolios which are more profitable are riskier, as well. This is the case both in the semivariance model and in the CVaR model. 


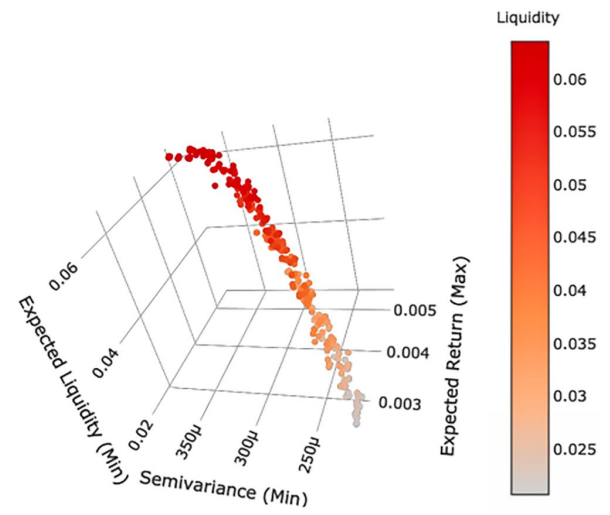

Figure 3. Pareto optimal front of the credibilistic mean-semivariance-liquidity model

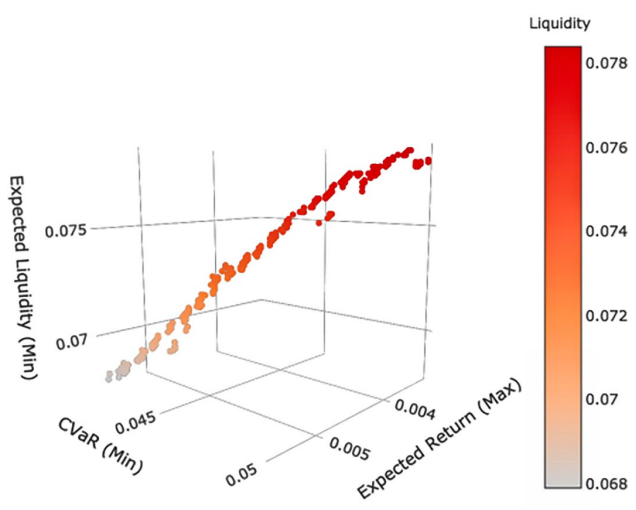

Figure 4. Pareto optimal front of the credibilistic mean-CVaR-liquidity model

Table 1. Partial correlation matriz with Spearman's rank

\begin{tabular}{|l|c|c|c|c|c|c|}
\cline { 2 - 7 } \multicolumn{1}{c|}{} & \multicolumn{3}{c|}{ Semivariance model } & \multicolumn{3}{c|}{ CVaR model } \\
\cline { 2 - 7 } \multicolumn{1}{c|}{} & Return & Risk & Liquidity & Return & Risk & Liquidity \\
\hline Return & 1.000 & & & 1.000 & & \\
\hline Risk & $0.808^{* *}$ & 1.000 & & $0.999^{\star *}$ & 1.000 & \\
\hline Liquidity & $-0.815^{\star *}$ & $0.957^{* *}$ & 1.000 & -0.060 & 0.024 & 1.000 \\
\hline
\end{tabular}

Note: ${ }^{* \star}$ Correlation is significant at the 0.01 level.

Regarding liquidity, in the semivariance model, more liquid portfolios are riskier, but less profitable. Conversely, less liquid portfolios are less risky and more profitable. This relationship between liquidity and risk can be explained by the fact that more liquid assets are traded more often and therefore their price may change more often, which means that their volatility may rise compared to less traded assets. Regarding the liquidity-return correlation, the result suggests that companies which are traded more often are not so profitable than those with less trades.

In the CVaR model, the correlation between liquidity and return and liquidity and risk is not significant. This does not necessarily mean that there is no correlation between these variables, but the correlation can be nonlinear. In fact, as can be observed in Figure 5, in the CVaR model, there is a clear nonlinear correlation between liquidity and return (Figure $5 \mathrm{~d}$ ) and liquidity and risk (Figure 5f).

Once the efficient frontier is obtained, a specific portfolio must be selected. Obviously, in a realistic investment scenario, investors need to pick a portfolio along the Pareto optimal front (Figure 3) that meets his/her preferences. As explained above, in the case of the credibilistic semivariance model, we have chosen the Sortino ratio as the method to pick the optimal portfolio, and the STARR ratio, in the case of the credibilistic CVaR model. Using a 5 -year long rolling window, a total of 20 portfolios are selected for each model. The evolution of each portfolio is tracked during 6 months and then the procedure is repeated to get 
a renewed portfolio. The performance of the models regarding return, risk and liquidity and the comparison with the benchmark are shown in Table 2.

Table 2 shows that both models beat the benchmark regarding return and risk in the period analyzed. The portfolios optimized along the 10 years have obtained more return and were less risky than the benchmark. When comparing the semivariance and the CVaR models, Table 2 shows that the semivariance model had better results in terms of mean return, risk and liquidity. Furthermore, the standard deviation has been smaller for all these criteria.

Semivariance model

a) Downside Risk vs. Expected Return

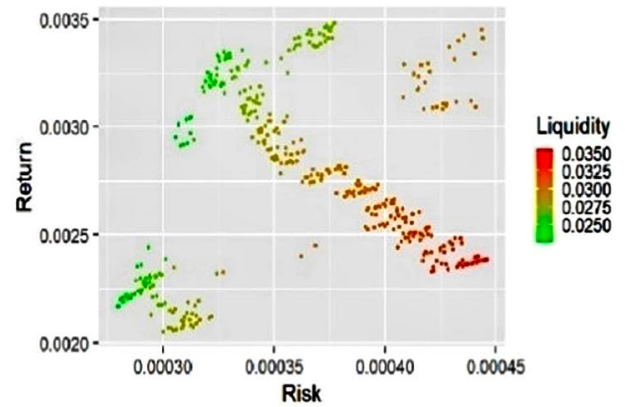

c) Expected Liquidity vs. Expected Return

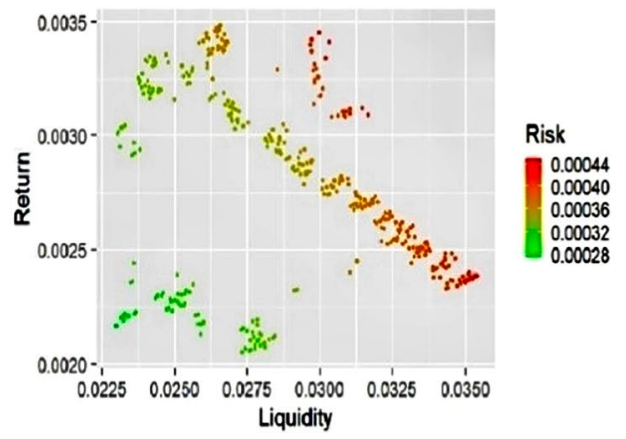

e) Downside Risk vs. Expected Liquidity

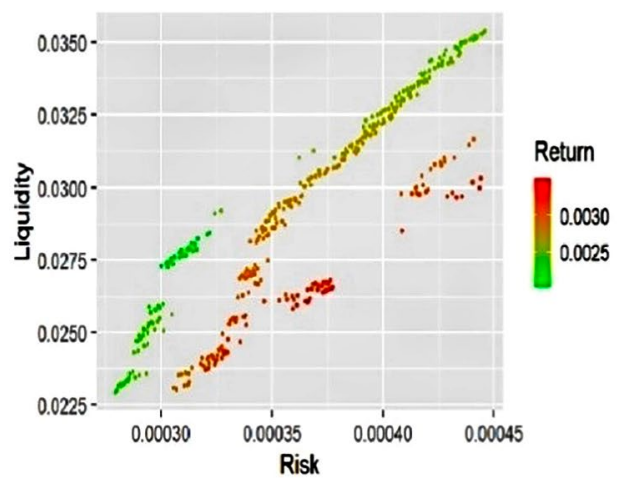

CVaR model

b) Downside Risk vs. Expected Return

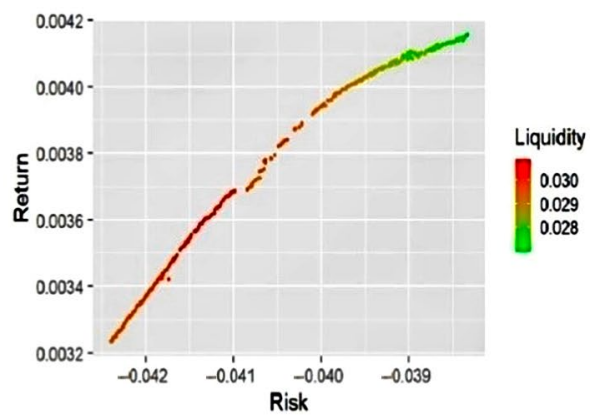

d) Expected Liquidity vs. Expected Return

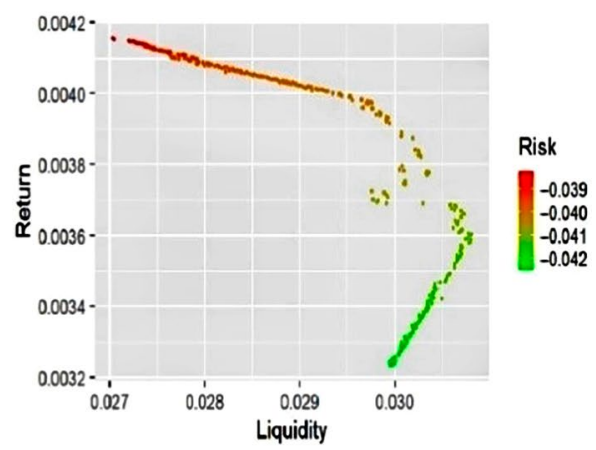

f) Downside Risk vs. Expected Liquidity

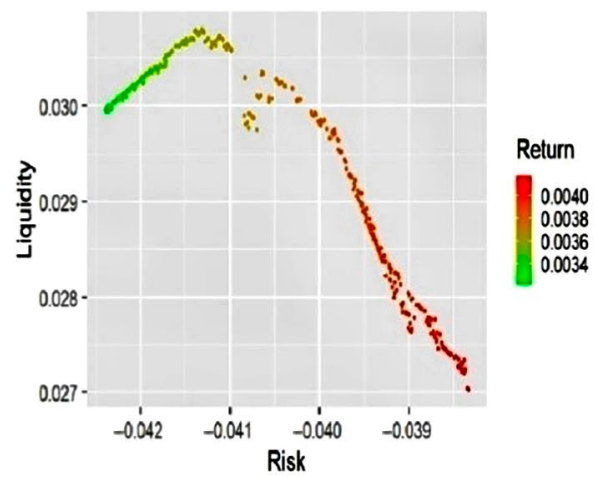

Figure 5. Distribution of the Pareto optimal front in the bivariate dimensions 
Table 2. Mean values and standard deviation for return, risk and liquidity of the credibilistic models and the ETF S\&P100

\begin{tabular}{|l|c|c|c|}
\cline { 2 - 4 } \multicolumn{1}{c|}{} & Return & Risk & Liquidity \\
\hline \multirow{2}{*}{ Semivariance Model } & 0.0029 & 0.0013 & 0.0665 \\
& $(0.0052)$ & $(0.0013)$ & $(0.0759)$ \\
\hline \multirow{2}{*}{ CVaR Model } & 0.0023 & 0.0015 & 0.0639 \\
& $(0.0055)$ & $(0.0022)$ & $(0.0733)$ \\
\hline \multirow{2}{*}{ ETF S\&P 100 } & -0.0010 & 0.0435 & - \\
& $(0.0214)$ & $(0.0613)$ & \\
\hline
\end{tabular}

Note: The value of the standard deviation is in parentheses.

A comparison regarding of the models and the ETF regarding liquidity is not been possible due to the lack of information about the liquidity of the ETF. To allow for a more insightful description of dispersion, values in Table 2 have been additionally depicted in Figure 6 . This way, differences between distributions are highlighted at a glance.

These results show that the applied multiobjective portfolio selection models may be helpful for investment managers who want to consider additional criteria together with the return and risk. This conclusion can be drawn as well when analyzing the out-of-sample evolution of results (Figure 7) and risk (Figure 8). Figure 7 shows the cumulative return of the portfolios along the 10-year period under scrutiny, during which portfolios were rebalanced twice a year. The evolution of return of the two credibilistic models shows a positive upward trend, whereas the evolution of the ETF considerably differs.

a) Return

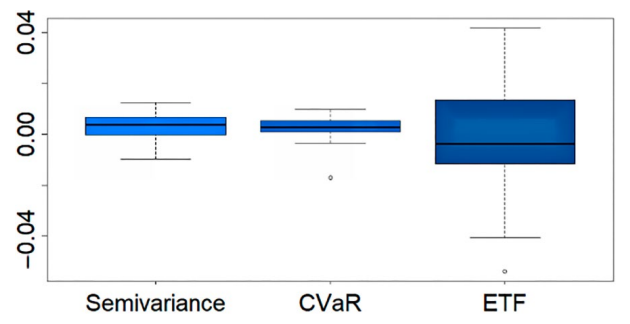

b) Risk

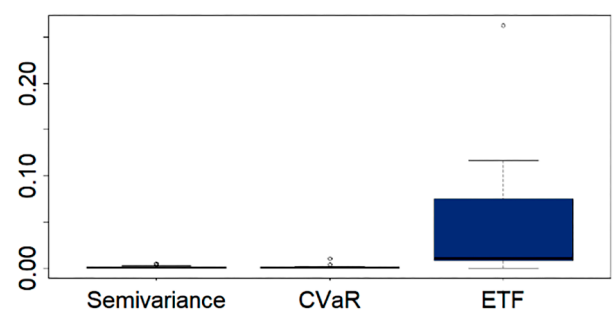

c) Liquidity

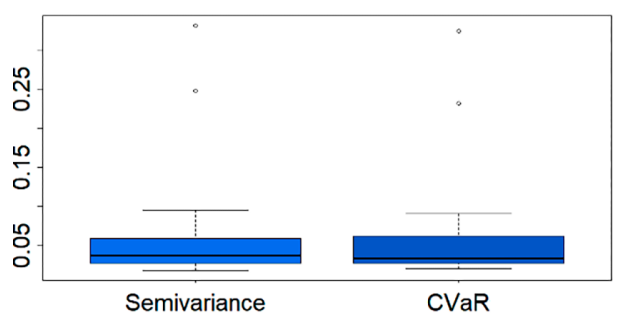

Figure 6. Boxplot graphs with return, risk and liquidity of the credibilistic models and the benchmark 
The evolution of the risk of the different portfolios obtained and the benchmark is drawn in Figure 8. Once again, it is evident that the performance of both credibilistic models along the period analyzed is much better than the performance of the ETF.

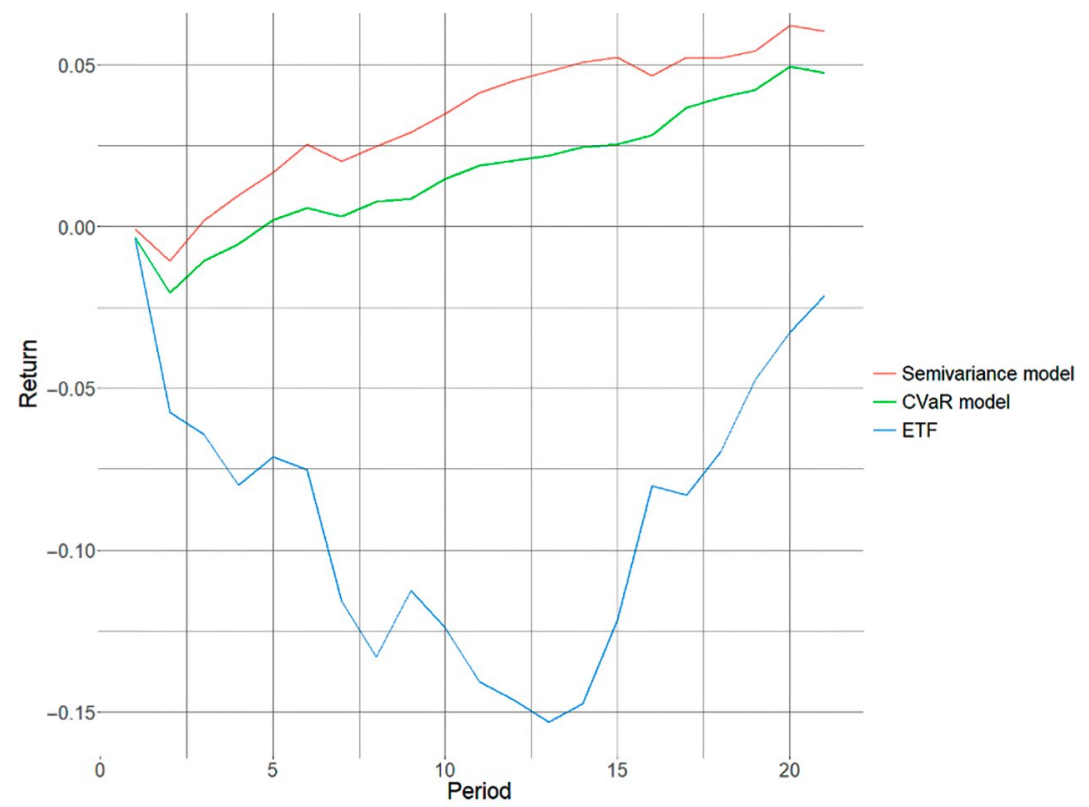

Figure 7. Evolution of the cumulative return

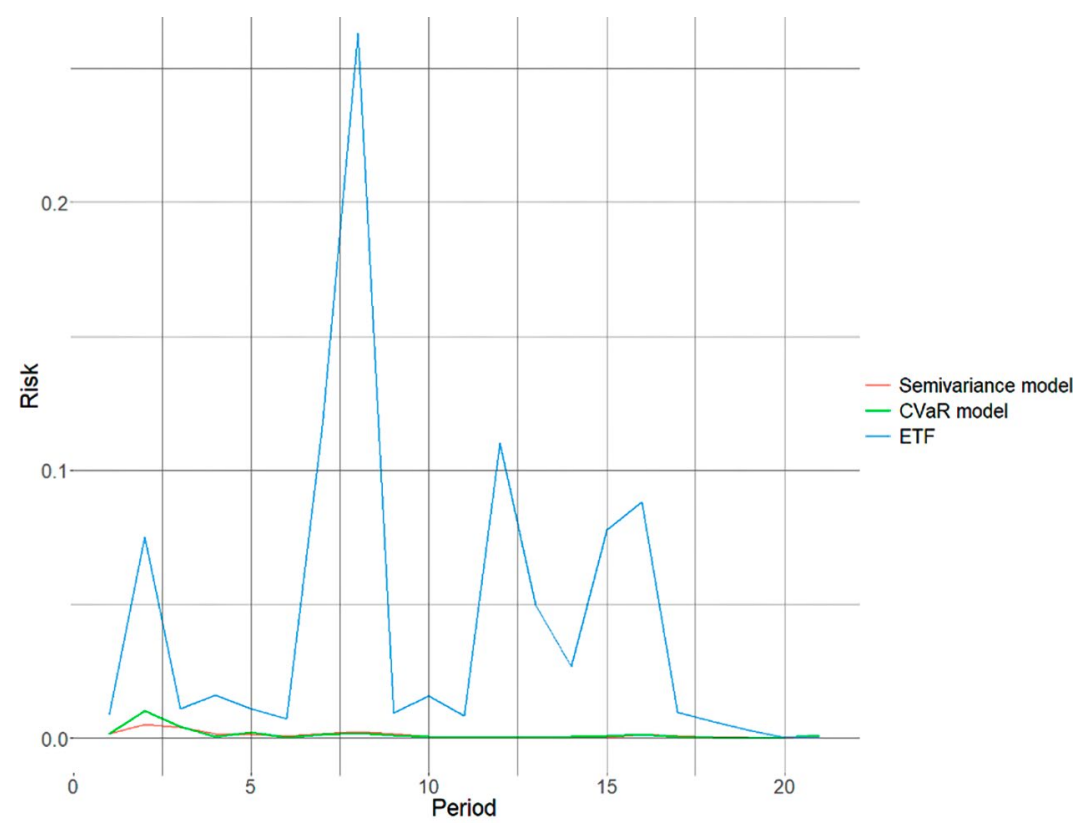

Figure 8. Evolution of risk 


\section{Conclusions}

Portfolio selection is one of the most dynamic topics in modern financial theory. Traditionally, the portfolio selection problem has been addressed under conditions of certainty and considering solely return and risk as decision criteria. More recently, other approaches have been introduced to cope with uncertain scenarios and to include more variables in the decision-making process. This paper extends the stochastic mean-variance model to a credibilistic multiobjective model in which return, risk and liquidity are employed to measure portfolio performance. In order to quantify the uncertainty of the future returns and the liquidity of each risky asset, this study uses trapezoidal fuzzy numbers. As risk measures, both the semivariance and the CVaR have been used. The Non dominated Sorting Genetic Algorithm II (NSGA-II) is applied to select efficient portfolios in the fuzzy return-risk-liquidity trade-off in the presence of cardinality constraint and upper and lower bound constraints and to create the efficient frontier. The Sortino ratio and the STARR ratio have been employed, depending on the risk measure used, to select one efficient portfolio among those located on the efficient frontier.

To illustrate the usefulness of the proposed model and the solution approach for the multiobjective portfolio selection, this paper presents a realistic empirical study on the S\&P100 stock index. The two credibilistic models are compared with the ETF S\&P100 as benchmark. We use the Sortino ratio in the case of the credibilistic semivariance model and the STARR ratio in the case of the credibilistic CVaR model in order to select the optimal portfolio. A total of 20 portfolios are selected for each model by using a 5 -year long rolling window. Then, the evolution of each portfolio is tracked during 6 months and afterwards this procedure is repeated to select a new portfolio. Results show that the models can beat the ETF in terms of return and risk in the period analyzed, from 2008 until 2018.

In view of the above discussions, this study concludes that the proposed model provides decision-makers with an effective and practicable alternative to solve the portfolio selection problem. Considering both uncertainty and real-life investment criteria, our approach can be useful for academics and practitioners interested in active investment strategies.

Further research should be carried out to test the model in a fuzzy random environment, or extend it to a multi-period portfolio selection problem. Furthermore, it might be interesting to identify and add other realistic criteria and constraints faced by investors such as round-lots, transaction costs, pre-assignment, etc.

\section{References}

Acerbi, C., \& Tasche, D. (2002). On the coherence of expected shortfall. Journal of Banking \& Finance, 26(7), 1487-1503. https://doi.org/10.1016/S0378-4266(02)00283-2

Ahmed, A., Ali, R., Ejaz, A., \& Ahmad, M. I. (2018). Sectoral integration and investment diversification opportunities: Evidence from Colombo Stock Exchange. Entrepreneurship and Sustainability Issues, 5(3), 514-527. https://doi.org/10.9770/jesi.2018.5.3(8)

Arenas-Parra, M., Bilbao-Terol, A., \& Rodríguez-Uría, M. V. (2001). A fuzzy goal programming approach to portfolio selection. European Journal of Operational Research, 133(2), 287-297.

https://doi.org/10.1016/S0377-2217(00)00298-8 
Arribas, I., Espinós-Vañó, M. D., García, F., \& Tamosiuniene, R. (2019). Negative screening and sustainable portfolio diversification. Entrepreneurship and Sustainability Issues, 6(4), 1566-1586. https://doi.org/10.9770/jesi.2019.6.4(2)

Artzner, P., Delbaen, F., Eber, J. M., \& Heath, D. (1999). Coherent measures of risk. Mathematical Finance, 9(3), 203-228. https://doi.org/10.1111/1467-9965.00068

Bai, X.-J., \& Liu, Y.-K. (2015). CVaR reduced fuzzy variables and their second order moments. University of Sistan and Baluchestan, 12(5), 45-75. https://doi.org/10.22111/IJFS.2015.2111

Bawa, V. S. (1975). Optimal rules for ordering uncertain prospects. Journal of Financial Economics, 2(1), 95-121. https://doi.org/10.1016/0304-405X(75)90025-2

Bermúdez, J. D., Segura, J. V., \& Vercher, E. (2012). A multi-objective genetic algorithm for cardinality constrained fuzzy portfolio selection. Fuzzy Sets and Systems, 188(1), 16-26. https://doi.org/10.1016/j.fss.2011.05.013

Bezoui, M., Moulaï, M., Bounceur, A., \& Euler, R. (2019). An iterative method for solving a bi-objective constrained portfolio optimization problem. Computational Optimization and Applications, 72(2), 479-498. https://doi.org/10.1007/s10589-018-0052-9

Bi, T., Zhang, B., \& Wu, H. (2013). Measuring downside risk using high-frequency data: Realized downside risk measure. Communications in Statistics - Simulation and Computation, 42(4), 741-754. https://doi.org/10.1080/03610918.2012.655826

Carlsson, C., Fullér, R., \& Majlender, P. (2002). A possibilistic approach to selecting portfolios with highest utility score. Fuzzy Sets and Systems, 131(1), 13-21. https://doi.org/10.1016/S0165-0114(01)00251-2

Chen, W., \& Xu, W. (2019). A hybrid multiobjective bat algorithm for fuzzy portfolio optimization with real-world constraints. International Journal of Fuzzy Systems, 21(1), 291-307. https://doi.org/10.1007/s40815-018-0533-0

Choobineh, F., \& Branting, D. (1986). A simple approximation for semivariance. European Journal of Operational Research, 27(3), 364-370. https://doi.org/10.1016/0377-2217(86)90332-2

Deb, K., Agrawal, K., Pratap, A., \& Meyarivan, T. (2002). A fast elitist non-dominated sorting genetic algorithm for multi-objective optimization: NSGA-II. IEEE Transactions on Evolutionary Computation, 6(2), 182-197. https://doi.org/10.1109/4235.996017

Fang, Y., Lai, K. K., \& Wang, S. Y. (2006). Portfolio rebalancing model with transaction costs based on fuzzy decision theory. European Journal of Operational Research, 175(2), 879-893. https://doi.org/10.1016/J.EJOR.2005.05.020

Favre, L., \& Galeano, J. (2002). Mean-modified Value at Risk optimization with hedge funds. Journal of Alternative Investments, 5, 21-25. https://doi.org/10.3905/jai.2002.319052

Fishburn, P. C. (1977). Mean-risk analysis with risk associated with below-target returns. The American Economic Review, 67(2), 116-126.

García, F., González-Bueno, J., Guijarro, F., \& Oliver, J. (2020). Forecasting the environmental, social, and governance rating of firms by using corporate financial performance variables: A rough set approach. Sustainability, 12(8), 3324. https://doi.org/10.3390/su12083324

García, F., González-Bueno, J., Oliver, J., \& Riley, N. (2019a). Selecting socially responsible portfolios: A fuzzy multicriteria approach. Sustainability, 11(9), 2496. https://doi.org/10.3390/su11092496

García, F., González-Bueno, J., Oliver, J., \& Tamošiūnienè, R. (2019b). A credibilistic mean-semivariance-PER portfolio selection model for Latin America. Journal of Business Economics and Management, 20(2), 225-243. https://doi.org/10.3846/jbem.2019.8317

García, F., Guijarro, F., \& Moya, I. (2013). A multiobjective model for passive portfolio management: an application on the S\&P100 index. Journal of Business Economics and Management, 14(4), 758-775. https://doi.org/10.3846/16111699.2012.668859 
García, F., Guijarro, F., \& Oliver, J. (2018a). Index tracking optimization with cardinality constraint: a performance comparison of genetic algorithms and tabu search heuristics. Neural Computing and Applications, 30, 2625-2641. https://doi.org/10.1007/s00521-017-2882-2

García, F., Guijarro, F., Oliver, J., \& Tamošiūnienè, R. (2018b). Hybrid fuzzy neural network to predict price direction in the german DAX-30 index. Technological and Economic Development of Economy, 24(6), 2161-2178. https://doi.org/10.3846/tede.2018.6394

Goel, A., Sharma, A., \& Mehra, A. (2018). Index tracking and enhanced indexing using mixed conditional value-at-risk. Journal of Computational and Applied Mathematics, 335, 361-380. https://doi.org/10.1016/j.cam.2017.12.015

González-Bueno, J. (2019). Optimización multiobjetivo para la selección de carteras a la luz de la teoría de la credibilidad. Una aplicación en el mercado integrado latinoamericano. Editorial Universidad Pontificia Bolivariana.

Gupta, P., Inuiguchi, M., \& Mehlawat, M. K. (2011). A hybrid approach for constructing suitable and optimal portfolios. Expert Systems with Applications, 38(5), 5620-5632.

https://doi.org/10.1016/j.eswa.2010.10.073

Gupta, P., Inuiguchi, M., Mehlawat, M. K., \& Mittal, G. (2013a). Multiobjective credibilistic portfolio selection model with fuzzy chance-constraints. Information Sciences, 229, 1-17. https://doi.org/10.1016/j.ins.2012.12.011

Gupta, P., Mehlawat, M. K., Inuiguchi, M., \& Chandra, S. (2014a). Portfolio optimization using credibility theory. In fuzzy portfolio optimization. Studies in Fuzziness and Soft Computing (Vol. 316, pp. 127-160). Springer-Verlag Berlin Heidelberg. https://doi.org/10.1007/978-3-642-54652-5_5

Gupta, P., Mehlawat, M. K., Inuiguchi, M., \& Chandra, S. (2014b). Portfolio optimization with interval coefficients. In Fuzzy portfolio optimization. Studies in Fuzziness and Soft Computing (Vol. 316, pp. 33-59). Springer, Berlin, Heidelberg. https://doi.org/10.1007/978-3-642-54652-5_2

Gupta, P., Mehlawat, M. K., Kumar, A., Yadav, S., \& Aggarwal, A. (2020a). A credibilistic fuzzy DEA approach for portfolio efficiency evaluation and rebalancing toward benchmark portfolios using positive and negative returns. International Journal of Fuzzy Systems, 22(3), 824-843. https://doi.org/10.1007/s40815-020-00801-4

Gupta, P., Mehlawat, M. K., \& Saxena, A. (2010). A hybrid approach to asset allocation with simultaneous consideration of suitability and optimality. Information Sciences, 180(11), 2264-2285. https://doi.org/10.1016/J.INS.2010.02.007

Gupta, P., Mehlawat, M. K., Yadav, S., \& Kumar, A. (2020b). Intuitionistic fuzzy optimistic and pessimistic multi-period portfolio optimization models. Soft Computing, 24, 11931-11956. https://doi.org/10.1007/s00500-019-04639-3

Gupta, P., Mittal, G., \& Mehlawat, M. K. (2013b). Expected value multiobjective portfolio rebalancing model with fuzzy parameters. Insurance: Mathematics and Economics, 52(2), 190-203. https://doi.org/10.1016/j.insmatheco.2012.12.002

Heidari-Fathian, H., \& Davari-Ardakani, H. (2020). Bi-objective optimization of a project selection and adjustment problem under risk controls. Journal of Modelling in Management, 15(1), 89-111. https://doi.org/10.1108/JM2-07-2018-0106

Hilkevics, S., \& Semakina, V. (2019). The classification and comparison of business ratios analysis methods. Insights into Regional Development, 1(1), 48-57. https://doi.org/10.9770/ird.2019.1.1(4)

Huang, X. (2006). Fuzzy chance-constrained portfolio selection. Applied Mathematics and Computation, 177(2), 500-507. https://doi.org/10.1016/j.amc.2005.11.027

Huang, X. (2008). Mean-semivariance models for fuzzy portfolio selection. Journal of Computational and Applied Mathematics, 217(1), 1-8. https://doi.org/10.1016/j.cam.2007.06.009

Huang, X. (2009). A review of credibilistic portfolio selection. Fuzzy Optimization and Decision Making, 8(3), 263-281. https://doi.org/10.1007/s10700-009-9064-3 
Huang, X. (2010). Portfolio analysis, from probabilistic to credibilistic and uncertain approaches (Vol. 250). Springer Berlin Heidelberg. https://doi.org/10.1007/978-3-642-11214-0

Huang, X. (2017). A review of uncertain portfolio selection. Journal of Intelligent and Fuzzy Systems, 32(6), 4453-4465. https://doi.org/10.3233/JIFS-169211

Huang, X., \& Di, H. (2016). Uncertain portfolio selection with background risk. Applied Mathematics and Computation, 276, 284-296. https://doi.org/10.1016/j.amc.2015.12.018

Huang, X., \& Wang, X. (2019). International portfolio optimization based on uncertainty theory. Optimization. https://doi.org/10.1080/02331934.2019.1705821

Huang, X., \& Yang, T. (2020). How does background risk affect portfolio choice: An analysis based on uncertain mean-variance model with background risk. Journal of Banking and Finance, 111, 105726. https://doi.org/10.1016/j.jbankfin.2019.105726

Jalota, H., Thakur, M., \& Mittal, G. (2017a). Modelling and constructing membership function for uncertain portfolio parameters: A credibilistic framework. Expert Systems with Applications, 71, 40-56. https://doi.org/10.1016/j.eswa.2016.11.014

Jalota, H., Thakur, M., \& Mittal, G. (2017b). A credibilistic decision support system for portfolio optimization. Applied Soft Computing, 59, 512-528. https://doi.org/10.1016/j.asoc.2017.05.054

Kaplan, P. D., \& Alldredge, R. H. (1997). Semivariance in risk-based index construction. The Journal of Investing, 6(2), 82-87. https://doi.org/10.3905/joi.1997.408419

Keating, C., \& Shadwick, W. F. (2002). A universal performance measure. Journal of Performance Measurement, 6(3), 59-84.

Konno, H., \& Yamazaki, H. (1991). Mean-absolute deviation portfolio optimization model and its applications to Tokyo stock market. Management Science, 37(5), 519-531. https://doi.org/10.1287/mnsc.37.5.519

Li, B., Zhu, Y., Sun, Y., Aw, G., \& Teo, K. L. (2018). Multi-period portfolio selection problem under uncertain environment with bankruptcy constraint. Applied Mathematical Modelling, 56, 539-550. https://doi.org/10.1016/J.APM.2017.12.016

Li, H. Q., \& Yi, Z. H. (2019). Portfolio selection with coherent Investor's expectations under uncertainty. Expert Systems with Applications, 133, 49-58. https://doi.org/10.1016/j.eswa.2019.05.008

Li, X., \& Qin, Z. (2014). Interval portfolio selection models within the framework of uncertainty theory. Economic Modelling, 41, 338-344. https://doi.org/10.1016/j.econmod.2014.05.036

Liagkouras, K., \& Metaxiotis, K. (2015). Efficient portfolio construction with the use of multiobjective evolutionary algorithms: Best practices and performance metrics. International Journal of Information Technology \& Decision Making, 14(03), 535-564. https://doi.org/10.1142/S0219622015300013

Liu, B. (2004). Uncertainty theory: an introduction to its axiomatic foundations (Vol. 154). SpringerVerlag Berlin Heidelberg.

Liu, B. (2007). Uncertainty theory an introduction to its axiomatic foundations (2nd ed.). Springer-Verlag Berlin Heidelberg.

Liu, B., \& Liu, Y. K. (2002). Expected value of fuzzy variable and fuzzy expected value models. IEEE Transactions on Fuzzy Systems, 10(4), 445-450. https://doi.org/10.1109/TFUZZ.2002.800692

Liu, N., Chen, Y., \& Liu, Y. (2018). Optimizing portfolio selection problems under credibilistic CVaR criterion. Journal of Intelligent and Fuzzy Systems, 34(1), 335-347. https://doi.org/10.3233/JIFS-171298

Liu, Y. J., \& Zhang, W. G. (2018). Multiperiod fuzzy portfolio selection optimization model based on possibility theory. International Journal of Information Technology and Decision Making, 17(3), 941-968. https://doi.org/10.1142/S0219622018500190

Mansour, N., Cherif, M. S., \& Abdelfattah, W. (2019). Multi-objective imprecise programming for financial portfolio selection with fuzzy returns. Expert Systems with Applications, 138, 112810. https://doi.org/10.1016/j.eswa.2019.07.027 
Markowitz, H. (1952). Portfolio selection. The Journal of Finance, 7(1), 77-91. https://doi.org/10.1111/j.1540-6261.1952.tb01525.x

Markowitz, H. (1959). Portfolio selection: efficient diversification of investments. Jhon Wiley \& Sons, Inc.

Markowitz, H., Todd, P., Xu, G., \& Yamane, Y. (1993). Computation of mean-semivariance efficient sets by the Critical Line Algorithm. Annals of Operations Research, 45(1), 307-317. https://doi.org/10.1007/BF02282055

Martin, R., Rachev, S., \& Siboulet, F. (2003). Phi-alpha optimal portfolios and extreme risk management. The Best of Wilmott 1: Incorporating the Quantitative Finance Review, 1, 223-248. https://doi.org/10.1002/wilm.42820030619

Mehlawat, M. K. (2016). Credibilistic mean-entropy models for multi-period portfolio selection with multi-choice aspiration levels. Information Sciences, 345, 9-26. https://doi.org/10.1016/j.ins.2016.01.042

Mehlawat, M. K., Gupta, P., Kumar, A., Yadav, S., \& Aggarwal, A. (2020). Multi-objective fuzzy portfolio performance evaluation using data envelopment analysis under credibilistic framework. IEEE Transactions on Fuzzy Systems, 1-1. https://doi.org/10.1109/tfuzz.2020.2969406

Mehralizade, R., Amini, M., Sadeghpour Gildeh, B., \& Ahmadzade, H. (2020). Uncertain random portfolio selection based on risk curve. Soft Computing, 24, 13331-13345. https://doi.org/10.1007/s00500-020-04751-9

Moeini, M. (2019). Solving the index tracking problem: a continuous optimization approach. Central European Journal of Operations Research, 1-29. https://doi.org/10.1007/s10100-019-00633-0

Morgan, J. P. (1996). Riskmetrics technical document (4th ed.). Morgan Guaranty Trust Company of New York.

Narkunienè, J., \& Ulbinaitè, A. (2018). Comparative analysis of company performance evaluation methods. Entrepreneurship and Sustainability Issues, 6(1), 125-138. https://doi.org/10.9770/jesi.2018.6.1(10)

Palanikumar, K., Latha, B., Senthilkumar, V. S., \& Karthikeyan, R. (2009). Multiple performance optimization in machining of GFRP composites by a PCD tool using non-dominated sorting genetic algorithm (NSGA-II). Metals and Materials International, 15(2), 249-258. https://doi.org/10.1007/s12540-009-0249-7

Pflug, G. C. (2000). Some remarks on the value-at-risk and the conditional value-at-risk. In S. P. Uryasev (Ed.), Probabilistic constrained optimization. nonconvex optimization and its applications (Vol. 49, pp. 272-281). Springer, Boston, MA. https://doi.org/10.1007/978-1-4757-3150-7_15

Rockafellar, R. T., \& Uryasev, S. (2000). Optimization of conditional value-at-risk. Journal of Risk, 2(3), 21-41. https://doi.org/10.21314/JOR.2000.038

Rockafellar, R. T., \& Uryasev, S. (2002). Conditional value-at-risk for general loss distributions. Journal of Banking \& Finance, 26(7), 1443-1471. https://doi.org/10.1016/S0378-4266(02)00271-6

Rubio, A., Bermúdez, J. D., \& Vercher, E. (2016). Forecasting portfolio returns using weighted fuzzy time series methods. International Journal of Approximate Reasoning, 75, 1-12. https://doi.org/10.1016/J.IJAR.2016.03.007

Saborido, R., Ruiz, A. B., Bermúdez, J. D., Vercher, E., \& Luque, M. (2016). Evolutionary multi-objective optimization algorithms for fuzzy portfolio selection. Applied Soft Computing, 39, 48-63. https://doi.org/10.1016/j.asoc.2015.11.005

Sharpe, W. F. (1966). Mutual fund performance. The Journal of Business, 39(1), 119-138. https://doi.org/10.1086/294846

Sharpe, W. F. (1994). The sharpe ratio. The Journal of Portfolio Management, 21(1), 49-58. https://doi.org/10.3905/jpm.1994.409501

Sortino, F. A., \& Price, L. N. (1994). Performance measurement in a downside risk framework. The Journal of Investing, 3(3), 59-64. https://doi.org/10.3905/joi.3.3.59 
Speranza, M. (1993). Linear programming models for portfolio optimization. Finance, 14, 107-123.

Srinivas, N., \& Deb, K. (1994). Muiltiobjective optimization using nondominated sorting in genetic algorithms. Evolutionary Computation, 2(3), 221-248. https://doi.org/10.1162/evco.1994.2.3.221

Treynor, J. L. (1965). How to rate management of investment funds. Harvard Business Review, 1, 63-75.

Vercher, E., \& Bermúdez, J. D. (2012). Fuzzy portfolio selection models: A numerical study. In M. Doumpos, C. Zopounidis, \& P. M. Pardalos (Eds.), Financial decision making using computational intelligence. Springer optimization and its applications (Vol. 70, pp. 253-280). Springer, Boston, MA. https://doi.org/10.1007/978-1-4614-3773-4_10

Vercher, E., \& Bermúdez, J. D. (2013). A possibilistic mean-downside risk-skewness model for efficient portfolio selection. IEEE Transactions on Fuzzy Systems, 21(3), 585-595. https://doi.org/10.1109/TFUZZ.2012.2227487

Vercher, E., \& Bermúdez, J. D. (2015). Portfolio optimization using a credibility mean-absolute semideviation model. Expert Systems with Applications, 42(20), 7121-7131. https://doi.org/10.1016/j.eswa.2015.05.020

Vercher, E., Bermúdez, J. D., \& Segura, J. V. (2007). Fuzzy portfolio optimization under downside risk measures. Fuzzy Sets and Systems, 158(7), 769-782. https://doi.org/10.1016/j.fss.2006.10.026

Wang, S., \& Zhu, S. (2002). On fuzzy portfolio selection problems. Fuzzy Optimization and Decision Making, 1(4), 361-377. https://doi.org/10.1023/A:1020907229361

Yue, W., \& Wang, Y. (2017). A new fuzzy multi-objective higher order moment portfolio selection model for diversified portfolios. Physica A: Statistical Mechanics and Its Applications, 465, 124-140. https://doi.org/10.1016/j.physa.2016.08.009

Yue, W., Wang, Y., \& Xuan, H. (2019). Fuzzy multi-objective portfolio model based on semi-variancesemi-absolute deviation risk measures. Soft Computing, 23(17), 8159-8179. https://doi.org/10.1007/s00500-018-3452-y

Zadeh, L. A. (1965). Fuzzy sets. Information and Control, 8(3), 338-353. https://doi.org/10.1016/S0019-9958(65)90241-X

Zhai, J., \& Bai, M. (2018). Mean-risk model for uncertain portfolio selection with background risk. Journal of Computational and Applied Mathematics, 330, 59-69. https://doi.org/10.1016/j.cam.2017.07.038

Zhao, Z., Wang, H., Yang, X., \& Xu, F. (2020). CVaR-cardinality enhanced indexation optimization with tunable short-selling constraints. Applied Economics Letters, 1-7.

https://doi.org/10.1080/13504851.2020.1740156 